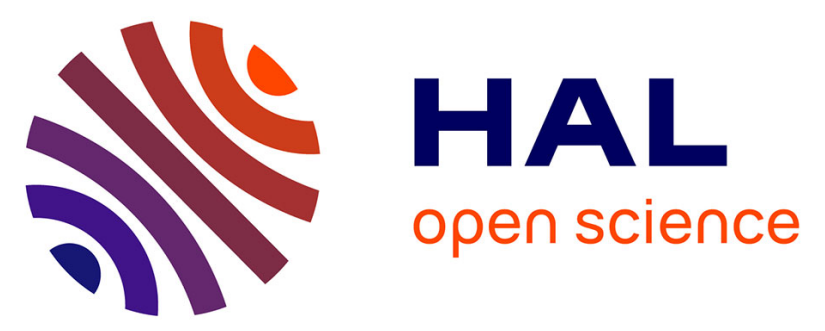

\title{
Information that Should be Given to HIV Cohort Participants During Ongoing Research: The Viewpoints of Patient Representatives and Research Professionals.
} Sandra Franrenet, Grégoire Moutel, François Raffi, François Dabis, Mathias Bruyand, Christian Hervé, Catherine Leport, Nathalie Duchange

\section{To cite this version:}

Sandra Franrenet, Grégoire Moutel, François Raffi, François Dabis, Mathias Bruyand, et al.. Information that Should be Given to HIV Cohort Participants During Ongoing Research: The Viewpoints of Patient Representatives and Research Professionals.. Journal of Empirical Research on Human Research Ethics, 2011, 6 (4), pp.76-83. 10.1525/jer.2011.6.4.76 . inserm-00658527

\section{HAL Id: inserm-00658527 https://www.hal.inserm.fr/inserm-00658527}

Submitted on 10 Jan 2012

HAL is a multi-disciplinary open access archive for the deposit and dissemination of scientific research documents, whether they are published or not. The documents may come from teaching and research institutions in France or abroad, or from public or private research centers.
L'archive ouverte pluridisciplinaire HAL, est destinée au dépôt et à la diffusion de documents scientifiques de niveau recherche, publiés ou non, émanant des établissements d'enseignement et de recherche français ou étrangers, des laboratoires publics ou privés. 


\section{Information that Should be Given to HiV Cohort Participants During Ongoing Research: The Viewpoints of Patient Representatives and Research Professionals}

\author{
Sandra Franrenet and Grégoire Moutel \\ Université Paris Descartes \\ FRANÇOIS RAFFI \\ CHU de Nantes \\ François Dabis and Mathias Bruyand \\ Inserm U897 \\ Christian Hervé \\ Université Paris Descartes \\ CATHERINE LEPORT \\ Université Paris Diderot, Inserm UMR 738 \\ Nathalie Duchange \\ Université Paris Descartes
}

\begin{abstract}
WHILE INVESTIGATORS HAVE A DUTY TO provide research participants with summary findings at the end of a study, providing general information during the course of research is rarely considered. However, this raises an important ethical issue in the context of long-term studies such as cohorts or biobanks. We investigated this issue in the context of two ANRS cohorts of HIV-infected patients, AQUITAINE and COPILOTE. Face-to-face interviews were conducted with HIV patient representatives and research professionals concerning the delivery of information in the course of the research. Respondents stated that participants wish to be informed of research results (both aggregate and individual) but also expect general information about the cohort itself, research progression, and what their participation may provide. It was concluded that information provided during the course of the research may help participants to distinguish between care and research. The essential role of clinicians-investigators in providing information was emphasized.
\end{abstract}

KEY WORDS: cohort, information after inclusion, research participants, HIV, therapeutic misconception
Received: May 13, 2011; revised: August 7, 2011

$\mathrm{P}$ ROVIDING RESEARCH PARTICIPANTS WITH summary results upon completion of a study has been recognized as an important ethical duty (World Medical Association, 2000; Council for International Organizations of Medical Sciences, 2002; Fernandez, Kodish, \& Weijer, 2003; Knoppers et al., 2006). Empirical studies concerning communication of research results (reviewed by Shalowitz \& Miller, 2008) have revealed the complexity of this issue in terms of the impact of research results, the distinction between aggregate and individual results, and the potential impact of the information on participants, as well as barriers for investigators.

Ongoing communication with study participants is rarely considered, although this issue is particularly relevant in the context of long-term studies where summary results may not be available for several years after the study begins. Such communication might occur through investigator-initiated newsletters (Moutel et al., 2005; McCarty et al., 2011). Miller et al. (2011) recently reported on the importance of "non-results information," a practice developed by a number of genetics researchers whom they surveyed. McCarty et al. (2011) state that a newsletter in a population-based biobank can play a key role in maintaining trust, reminding people of their participation, and allowing participants to withdraw in case of protocol changes. In a previous report, we also underlined the importance of providing information to keep participants updated with research progress in a sub-study including a biobank (Moutel et al., 2005). Giving information about the genetic markers to be studied during the progress of research was considered an important aspect of respecting participants and acknowledging the value of their samples. It was considered necessary to ensure that the initial informed consent remained valid over time due to the various

\footnotetext{
Journal of Empirical Research on Human Research Ethics, PP. 76-83. PRINT ISSN 1556-2646, ONLINE ISSN 1556-2654. (C) 2011 BY JOAN SIEBER. ALl RIGHTS RESERVED. PLEASE DIRECT ALL REQUESTS FOR PERMISSIONS TO PHOTOCOPY OR REPRODUCE ARTICLE CONTENT THROUGH THE UNIVERSITY OF CALIFORNIA PRESS'S RIGHTS AND PERMISSIONS WEBSITE, HTTP://WWW.UCPRESSJOURNALS.COM/REPRINTINFO.ASP. DOI: $10.1525 /$ jer.2011.6.4.76
} 
intervening scientific choices made. Empirical support for this practice has been described in a study by Smith et al. (2011) that underlines the importance of keeping participants informed over time via "ongoing consent."

The purpose of this study was to learn about the attitudes of patient representatives and research professionals concerning the value of ongoing communication in the context of two cohorts of HIV-infected patients. First, we chose to explore the opinion of patient advocates within the TRT-5, a coalition of French HIV/AIDS organizations which has been working for years with the French Agence Nationale de Recherches sur le Sida et les hépatites virales (ANRS) to improve access to research information (Collard \& Taéron, 2004; Moutel et al., 2005). Second, we sought the perspectives of research professionals, including principal investigators, clinicians, and researchers. In this category, we included a representative of the research agency. Participants' perspectives will be the object of a subsequent report.

\section{Method}

Two cohorts were chosen for this study: AQUITAINE (Msellati et al., 1990) and APROCO-COPILOTE (COPILOTE) (Le Moing et al., 2002). Details of the cohorts are given in the supplementary online content (http://dx.doi.org/10.1525/jer.2011.6.4.76).

As summarized in Table 1, the cohorts differ. AQUITAINE is an observational cohort based on followup consultations in the southwest of France. COPILOTE is a multicenter study with follow-up consultations every four months including blood samples and selfadministered questionnaires. In AQUITAINE, information is given to clinicians-investigators, who are invited every three months to a meeting at which both the projects and the results are discussed. Newsletters to participants have been developed in two sub-studies since 2009. In COPILOTE, information to both clinicians-investigators and participants exists since the study's inception (COPILOTE being the continuation of the APROCO cohort). An annual newsletter dedicated to the participating physicians was coupled with a participant newsletter. This achieves two objectives: first, it informs the physicians, and second, it allows the physicians to deliver the participant newsletter during a medical consultation.

\section{Semi-directed Interviews}

\section{POPULATION INTERVIEWED}

We investigated the opinions of three groups: (1) the coordinators of TRT-5 (Traitements \& Recherche Thérapeutique 5) and of each of the eight associations comprising this coalition involved in HIV clinical research: Actions Traitements, Act Up-Paris, Aides, Arcat, Dessine Moi Un Mouton, Nova Dona, Sida info Service, and Sol En Si; (2) three categories of professionals of AQUITAINE and COPILOTE (the principal investigators in charge of coordinating the project and who were involved in patient care, either directly or indirectly; clinicians involved in patient follow-up; and researchers not involved in clinical care); and (3) the Director of the ANRS, an agency that coordinates and

TABLE 1. Context of the Study: AQUITAINE and COPILOTE Cohorts.

\begin{tabular}{|c|c|c|}
\hline & AQUITAINE & COPILOTE \\
\hline \multirow[t]{3}{*}{ Inclusion } & 1987 & 1997-1999 (COPILOTE being the continuation of APROCO) \\
\hline & Still including & Ended in 2009 \\
\hline & HIV-positive individuals & HIV-positive individuals having started antiretroviral treatment \\
\hline Hospitals & Southwest of France & Multicenter \\
\hline Objective & $\begin{array}{l}\text { Study of the natural history } \\
\text { and undertreatment of HIV } \\
\text { infection }\end{array}$ & Study of the factors associated with long-term treatments \\
\hline Conditions for participants & $\begin{array}{l}\text { Data (standardized question- } \\
\text { naire) collected during each } \\
\text { medical consultation or } \\
\text { hospitalization }\end{array}$ & $\begin{array}{l}\text { Medical follow-up visits every four months } \\
\text { Blood sample taking } \\
\text { Questionnaires }\end{array}$ \\
\hline $\begin{array}{l}\text { Information for clinicians/ } \\
\text { investigators }\end{array}$ & $\begin{array}{l}\text { Scientific meetings every } \\
\text { three months on the cohort's } \\
\text { projects and results }\end{array}$ & $\begin{array}{l}\text { Regular scientific meetings } \\
10 \text { newsletters from 1999-2009 (includes information about } \\
\text { sub-studies) }\end{array}$ \\
\hline Information for participants & $\begin{array}{l}\text { Newsletters since } 2009 \text { in two } \\
\text { sub-studies including new } \\
\text { consent }\end{array}$ & $\begin{array}{l}10 \text { newsletters from 1999-2009 (includes information about } \\
\text { sub-studies) delivered during consultation }\end{array}$ \\
\hline
\end{tabular}


funds research on AIDS and viral hepatitis in France and developing countries.

The two coordinators of TRT-5, the cohort investigators of AQUITAINE and COPILOTE, and the Director of the ANRS were contacted during the first semester of 2009 by an e-mail describing the goal of the study and inviting them to a face-to-face interview. Their help was also requested to identify the resource persons to be interviewed in the associations comprising TRT- 5 and in both cohorts. Invitations were then sent by e-mail to each contact person.

\section{THE INTERVIEWS}

The interviews consisted of a series of questions designed to investigate the perception of the information available to cohort participants after they began participation in the research. Most questions were designed so that an initial "yes or no" response was sought before comments. Specific modifications to some questions were made according to the category of respondents interviewed (as specified in the results).

\section{DATA COLLECTION}

The interviews (about 1-1/2 hours long) were conducted either in person or by telephone. In either case, respondents were asked for their permission to record the interview and the anonymity of their responses was assured.

\section{DATA ANALYSIS}

The recorded interviews were fully transcribed. Each respondent was assigned a number and the data were entered into Excel. Tables were created for each question and for each category of respondents with their comments. A semi-quantitative analysis was performed according to the yes/no/other answers. The qualitative analysis was performed using a two-step procedure: (1) the ideas expressed by the respondents were identified and (2) the frequency of their occurrence was analyzed. Respondents' quotes were selected based on their relevance to the issue, independent of the frequency of occurrence of the idea expressed.

\section{Results}

A total of 27 interviews were conducted. All members of the TRT-5 group (11 in total) participated, including the two coordinators and the heads of the HIV patients' associations. Two associations did not participate due to a lack of a temporary representative to the TRT- 5 or because no contact was established. Of 17 professionals contacted, 16 agreed to be interviewed: the principal investigator, two researchers, and four clinicians from the AQUITAINE cohort (seven total); the two principal investigators, two researchers, and four clinicians from the COPILOTE cohort (eight total); and a representative of the ANRS working in the service of HIV/AIDS clinical and therapeutic research (designated by the Director of the ANRS). All respondents agreed to be recorded.

The results and salient points raised by the respondents during the interviews are presented below. Citations and expressions that were found relevant are presented in the supplementary online content.

\section{Question 1: What information after inclusion?}

To the question "Would you say that there is a lack of information to participants after their inclusion in a cohort?" a majority of patient representatives (9/11) answered "yes". In their comments, some qualified the lack as huge or reported the term "laboratory specimens" to express the feeling of participants. Others recognized that participants are not always interested in such information and that the situation is beginning to evolve. On the contrary, the two respondents who answered in the negative think that cohort participants are very well informed as compared to clinical trials.

The question was posed in a slightly different form to professionals: "Do you think that participants are waiting for information after their inclusion in a cohort?" Twelve out of 16 answered positively (5/7 of AQUITAINE, 6/8 of COPILOTE, and the representative of the ANRS). The respondents expressed that this is patient-dependent and that they do not really know the exact nature of the information expected. One of the COPILOTE professionals insisted on the importance to provide information "whether they ask for it or not," the feedback demonstrating respect toward participants.

Four answered in the negative (2/7 of AQUITAINE, 2/8 of COPILOTE). They mentioned lack of participant interest in research in general and the fact that participants are mostly interested in information concerning themselves. They reported that participants lose the feeling of belonging to a cohort after a while. One clinician stated that consultation was the opportunity to provide a reminder of participation by showing the general data obtained thanks to their participation (through a web site in this example).

Question 2: Have you ever had requests from people seeking information on the cohort in which they are participating?

Table 2 shows that only $9 / 27$ reported receiving requests. There were none in AQUITAINE. Among patient 
representatives, one commented that this was happening often, while others reported that this was rare or that the requests concerned clinical trials rather than cohorts. Most professionals of COPILOTE commented that the requests were rare or episodic, except for one professional who commented that such requests sometimes arose and stimulated further communication.

The main reason given for lack of requests was the lack of contact with participants (the two researchers in each cohort and one of the principal investigators). The others indicated that participants' requests mostly concerned clinical trials or cohort sub-studies.

The question was asked in a slightly different form to the ANRS representative: "Do you know if participants in cohorts request additional information after their inclusion in the study?" The answer was positive due to the request coming directly from the patient representatives with whom the institution works extensively.

\section{Question 3: What kind of information do you think that cohort participants would like to receive?}

As shown in Table 3, the most cited items were the "characteristics and life of the cohort" and "research results."
Patient representatives specified that information provided to participants about their cohort should contain basic elements concerning the cohort such as sociodemographic features, number of participants, general criteria for inclusion, and studies conducted on the data collected. Professionals from both cohorts also insisted that such information should include factual elements, such as what happens in the cohort, as well as giving general information about the state of health and the evolution of the disease for the patients included. It should also mention the implications of their participation for progress in HIV research. The ANRS representative stated that the participants should be able to follow the life of the cohort through the periodic provision of information. In addition, most patient representatives and professionals stated that participants expect both individual and aggregate results, including research results from sub-studies and from samples they provided.

Question 4: Do you think that, in most cases, the information you have mentioned is given to participants?

The three respondents who responded in Question 3 that they did not know what type of information

TABLE 2. Have you ever had requests from people seeking information on the cohort in which they are participating? (Question 2)

\begin{tabular}{lccccc}
\hline & & \multicolumn{3}{c}{ Professionals } \\
\cline { 3 - 5 } & $\begin{array}{c}\text { Patient } \\
\text { Representatives } \\
\mathrm{n}=11\end{array}$ & $\begin{array}{c}\text { AQUITAINE } \\
\text { Cohort } \\
\mathrm{n}=7\end{array}$ & $\begin{array}{c}\text { COPILOTE } \\
\text { Cohort } \\
\mathrm{n}=8\end{array}$ & $\begin{array}{c}\text { The } \\
\text { Representative } \\
\text { of ANRS }\end{array}$ & $\begin{array}{c}\text { Total } \\
\mathrm{n}=\mathbf{2 7}\end{array}$ \\
\hline Yes & 3 & 0 & 5 & 1 & 9 \\
No & 8 & 7 & 3 & 0 & 18 \\
\hline
\end{tabular}

TABLE 3. What kind of information do you think that cohort participants would like to receive? Spontaneous terms cited by the interviewees (Question 3).

\begin{tabular}{|c|c|c|c|c|c|}
\hline & \multirow[b]{2}{*}{$\begin{array}{c}\text { Patient } \\
\text { Representatives } \\
n=11\end{array}$} & \multicolumn{3}{|c|}{ Professionals } & \multirow[b]{2}{*}{$\begin{array}{l}\text { Total } \\
\mathrm{n}=27\end{array}$} \\
\hline & & $\begin{array}{c}\text { AQUITAINE } \\
\text { Cohort } \\
n=7\end{array}$ & $\begin{array}{l}\text { COPILOTE } \\
\text { Cohort } \\
n=8\end{array}$ & $\begin{array}{l}\text { The } \\
\text { Representative } \\
\text { of ANRS }\end{array}$ & \\
\hline $\begin{array}{l}\text { Characteristics and life } \\
\text { of the cohort }\end{array}$ & 8 & 4 & 2 & 1 & 15 \\
\hline Research results & 5 & 2 & 7 & 1 & 15 \\
\hline Impact for follow-up & 1 & 0 & 3 & 0 & 4 \\
\hline $\begin{array}{l}\text { Benefits issued from } \\
\text { participation }\end{array}$ & 2 & 0 & 1 & 0 & 3 \\
\hline HIV research in general & 0 & 2 & 1 & 0 & 3 \\
\hline Fate of the samples & 2 & 0 & 1 & 0 & 3 \\
\hline No information wished & 2 & 2 & 1 & 0 & 5 \\
\hline Do not know & 1 & 1 & 1 & 0 & 3 \\
\hline
\end{tabular}


participants expected were not asked this question. As shown in Table 4, only 8/24 respondents thought that the type of information they mentioned in Question 3 was effectively given to participants in most cases. The positive answers most frequently relied on the existence of the newsletter for participants in COPILOTE and on the existence of the newsletter for investigators allowing potential questions from the participants to be answered.

Among respondents who said that they did not think such information is typically provided, three categories of arguments were given:

1. Inadequate written information. The irregularity of the newsletter was mentioned as well as its lack of completeness and the failure of project administrators to ask participants to evaluate the newsletter. One deplored the fact that information is provided only at the end of the trials.

2. A lack of oral information. Patient representatives indicated that physicians do not always play their role in relaying research information, that they are not always informed about what is happening in the cohort, that they do not spend enough time delivering information to participants, that they do not explain in readily understood terminology, and that they rely on patient associations to provide information. One professional commented that it depends upon the good will of the physician.

3. A lack of resources. One patient representative deplored the lack of budget to establish a telephone line or a web site. Professionals pointed to a lack of dedicated personnel and a lack of human skill with patient communication.

Question 5: Do you think that participants are able to make the distinction between their research participation and medical care?

As shown in Table 5, only 6/27 respondents thought that participants are able to make this distinction. This category of respondents includes no patient representatives.

The ability to make the distinction between research participation and medical care is linked (according to the respondents) to the existence of specific elements due to the research. Professionals cited such elements as signature of consent, regular follow-up visits, existence of sub-studies, blood sample taking, questionnaires, and the length of the participation. Professionals of COPILOTE reported the existence of more such elements as compared to those of AQUITAINE.

The difficulty in making the distinction between research participation and medical care is associated

TABLE 4. Do you think that, in most cases, the information you have mentioned is given to participants? (Question 4)

\begin{tabular}{lccccc}
\hline & & \multicolumn{4}{c}{ Professionals } \\
\cline { 3 - 5 } & $\begin{array}{c}\text { Patient } \\
\text { Representatives } \\
\mathrm{n}=10\end{array}$ & $\begin{array}{c}\text { AQUITAINE } \\
\text { Cohort } \\
\mathrm{n}=6\end{array}$ & $\begin{array}{c}\text { COPILOTE } \\
\text { Cohort } \\
\mathrm{n}=7\end{array}$ & $\begin{array}{c}\text { The } \\
\text { Representative } \\
\text { of ANRS }\end{array}$ & $\begin{array}{c}\text { Total* } \\
\mathrm{n}=24\end{array}$ \\
\hline Yes & 2 & 1 & 4 & 1 & 8 \\
No & 6 & 3 & 2 & 0 & 11 \\
Do not know & 2 & 2 & 1 & 0 & 5 \\
\hline
\end{tabular}

* Those who answered that they did not know to Question 3 were not asked this question.

TABLE 5. Do you think that participants are able to make the distinction between their research participation and medical care? (Question 5)

\begin{tabular}{|c|c|c|c|c|c|}
\hline & \multirow[b]{2}{*}{$\begin{array}{c}\text { Patient } \\
\text { Representatives } \\
n=11\end{array}$} & \multicolumn{3}{|c|}{ Professionals } & \multirow[b]{2}{*}{$\begin{array}{l}\text { Total } \\
n=27\end{array}$} \\
\hline & & $\begin{array}{c}\text { AQUITAINE } \\
\text { Cohort } \\
n=7\end{array}$ & $\begin{array}{c}\text { COPILOTE } \\
\text { Cohort } \\
n=8\end{array}$ & $\begin{array}{l}\text { The } \\
\text { Representative } \\
\text { of ANRS }\end{array}$ & \\
\hline Yes & 0 & 3 & 2 & 1 & 6 \\
\hline No & 8 & 3 & 4 & 0 & 15 \\
\hline Patient dependent & 1 & 1 & 2 & 0 & 4 \\
\hline Do not know & 2 & 0 & 0 & 0 & 2 \\
\hline
\end{tabular}


with: (1) the non-interventional and observational nature of the research, (2) the fact that follow-up is part of the cohort, (3) the lack of specific elements asked of research participants, (4) failure of physicians to talk about research, (5) failure to receive any result from their participation, (6) participants forgetting that they belong to a cohort, and (7) care and research having long been confounded in the case of HIV. One respondent stated that patients sometimes wonder about the usefulness of their participation.

\section{Discussion}

The results of this exploratory study support the value of providing general information to research participants in an ongoing process. Through the perspective of patient representatives and cohort professionals we interviewed, participants wish to receive research results (both aggregate and individual), general information concerning the cohort in which they participate, and information regarding HIV research progress and what their participation may provide. Although our patient representative respondents deplored the lack of research information generally provided, some acknowledged the provision of information through the distribution of a newsletter.

The results also reveal the importance of ongoing information in reminding individuals of their research participation. Most respondents stressed the difficulty that research participants have with distinguishing between care and research, a situation described by Appelbaum, Roth, and Lidz (1982) as a therapeutic misconception. When research is mostly based on followup, it is difficult for participants to know which part is research and which part is care. Such a situation in which the benefits and burdens associated with each situation are confused for research participants has been described by Lazovski et al. (2009). For the respondents, the ability to make the distinction is associated with the existence of specific elements linked to the research (such as signed consent) and the existence of information. In support of this, professionals of COPILOTE (where more elements of research and information exist for participants) report that they receive requests from participants about the cohort, whereas there was no report of such requests in AQUITAINE. However, professionals of COPILOTE still think that it is difficult for participants to make the distinction between care and research. Interestingly, focus-group participants in a study by McCarty et al. (2011) suggested that each edition of the newsletter should remind participants of their enrollment in research. Our respondents also pointed out the essential role of physicians in reminding patients of their research participation. As examples of this, one professional reported, "perhaps I consider some exchanges spontaneous, although they actually originate from me," and another took advantage of medical consultations to remind patients that, "thanks to their participation, they have a valuable global follow-up tool."

Confusion between care and research may explain one surprising result obtained in this study: the rarity of requests for information from the participants. Smith et al. (2011) found a similar absence of questions. They describe additional reasons (lack of opportunity, not knowing whom to ask) to explain this contradiction.

Finally, the respondents in this study insisted that expectations are quite participant dependent. This is not surprising as the heterogeneous nature of participants' expectations regarding research information has been found in a number of studies (MacNeil \& Fernandez, 2006; Dixon-Woods et al., 2006; Murphy et al., 2008; Baret \& Godard, 2011). While this may appear as a difficulty in the construction of information and in the generalization of the findings, this should not be an argument for evading the duty to inform. As stated by one professional in this study, it is important to inform whether they take the information or not. McCarty et al. (2011) recommended against an initial opt-out option for receiving the study newsletter in one's consent form. They emphasized the need to provide study information to all participants after initial consent.

The limitations of our approach lie in the small number of respondents in each category and in the qualitative interpretation of the data. The specific context of the study also makes the generalization of the results difficult. Given that cohort participation was based on longterm medical follow-up has a number of implications in terms of the differentiation between the medical and research part of the activities.

\section{Best Practices}

Our study supports the idea that general information about ongoing research should be made available to participants and that the delivery of this information should be encouraged as a measure of respect as well as to generate interest, awareness, and commitment to research. As shown in this study, the availability of general information stimulates physicians to communicate with participants about the ongoing research. It also is a way of thanking the participants, and helping them to grasp the distinction between medical care and research. 


\section{Research Agenda}

There is a need for more studies on this issue with other disease entities, and in other cultural and national contexts. Furthermore, there is little evidence-based guidance as to the kinds of general information and global research results that are meaningful for research participants. To what extent do participants want to know about how their participation contributes to a better understanding of their disease? What is their interest in the state of research on their disease, given that the pace at which knowledge advances may be very slow in relation to their hope for personal recovery?

\section{Educational Implications}

When introducing students to the concept and operationalization of informed consent, concepts of ongoing provision of various types of information should also be explored in relation to various contexts of research.

\section{Acknowledgments}

We are grateful to all who agreed to participate in this study and be interviewed: the representative from the ANRS, the professionals of the AQUITAINE and COPILOTE cohorts, and the members of the TRT-5. Sandra Franrenet was supported by a doctoral fellowship from the ANRS. We thank Didier Pélaprat for his help in the revision of the manuscript.

\section{Author Note}

Address correspondence to: Nathalie Duchange, EA 4569, Laboratoire d'Ethique Médicale et de Médecine Légale, Faculté de médecine, Université Paris Descartes, 45 rue des Saints-Pères, 75006 Paris, France. Phone: 33(0)1 428641 35; Fax: 33(0)1 428641 33; E-MAIL: nathalie.duchange@inserm.fr.

\section{Authors' Biographical Sketches}

Sandra Franrenet is a doctoral candidate in the laboratory of medical ethics, at EA4569 in the Faculty of Medicine of Paris Descartes University, Paris, France. She has been working for more than two years at UNALS, the French National Union of Organisations against AIDS, as a coordinator.

Grégoire Moutel is a medical doctor, and codirector of EA4569 at the Faculty of Medicine of Paris
Descartes University, Paris, France. For the past ten years his major research themes have been the evolution of patients' rights, the inclusion of social aspects in health, the patient/doctor relationship, the protection of people participating in biomedical research, and all ethical issues related to the use of elements and products of human bodies.

François Raffi is Professor and Head of the Infectious and Tropical Diseases Unit of the Internal Medicine Department at the Hotel-Dieu University Hospital in Nantes, France, and Head of the AIDS Clinical Research Unit and AIDS Reference Center in Nantes. He is the principal investigator in several national (ANRS) and international Phase I-III trials in HIV infection therapy. $\mathrm{He}$ is a principal investigator of the ANRS CO8 APROCO-COPILOTE cohort.

François Dabis is Professor of Public Health at the Bordeaux Segalen University in Bordeaux, Inserm U897, France. He is the principal investigator of the ANRS CO3 AQUITAINE cohort and the ANRS C013 HPEAVIH cohort.

Mathias Bruyand is an epidemiologist at the Inserm U897 unit located in the Bordeaux School of Public Health (ISPED), Bordeaux Segalen University in Bordeaux, France. He is member of the methodology and epidemiology group of the "Grouped'Epidemiologie Clinique du Sida en Aquitaine" (GECSA) steering the ANRS CO3 AQUITAINE cohort.

Christian Hervé is Professor and Director of EA4569 at the Faculty of Medicine of Paris Descartes University, Paris, France. He is head of a service hospital at the Corentin Celton Hospital in Issy-Les-Moulineaux and head of ASDES, a network for the access to care, rights, and health education.

Catherine Leport is Professor at the Paris Diderot University, Inserm UMR 738, Paris, France. She is a specialist in Infectious and Tropical Diseases, and supervises the Regional Coordination for Epidemic and Biological Risk Unit, AP-HP. She is the Chair of the ANRS C08 APROCO-COPILOTE cohort. She is an expert in emerging infectious diseases and has worked on the specific issues of communication in this field.

Nathalie Duchange is a researcher at Inserm, working at the Faculty of Medicine of Paris Descartes University (EA4569, France), where she has been developing research on patient information in the practice of care and research. She is also involved at the Department of Scientific Information of INSERM in the dissemination of research results through Open Access initiatives. 


\section{References}

Appelbaum, P. S., Roth, L. H., \& Lidz, C. (1982). The therapeutic misconception: Informed consent in psychiatric research. International Journal of Law and Psychiatry, 5(3-4), 319-329.

BARET, L. \& GodARD, B. (2011). Opinions and intentions of parents of an autistic child toward genetic research results: Two typical profiles. European Journal of Human Genetics, 19(11), $1127-1132$.

Collard, V. \& TAÉron, C. (2004). Ethical aspects of clinical trials and patient informed-consent sheet: HIV/AIDS. Thérapie, 59(4), 407-411.

Council for International Organizations of Medical Sciences. (2002). International ethical guidelines for biomedical research involving human subjects. Retrieved from http://www.cioms.ch/publications/layout_ guide2002.pdf.

Dixon-Woods, M., Jackson, C., Windridge, K. C., \& Kenyon, S. (2006). Receiving a summary of the results of a trial: Qualitative study of participants' views. British Medical Journal, 332(7535), 206-210.

Fernandez, C. V., Kodish, E., \& Weijer, C. (2003). Informing study participants of research results: An ethical imperative. IRB, 25(3), 12-19.

Knoppers, B. M., Joly, Y., Simard, J., \& Durocher, F. (2006). The emergence of an ethical duty to disclose genetic research results: International perspectives. European Journal of Human Genetics, 14(11), 1170-1179.

Lazovski, J., Losso, M., Krohmal, B., Emanuel, E. J., Grady, C., \& WendleR, D. (2009). Benefits and burdens of participation in a longitudinal clinical trial. Journal of Empirical Research on Human Research Ethics, 4(3), 89-97.

Le Moing, V., Thiébaut, R., Chêne, G., Leport, C., Cailleton, V., Michelet, C., Fleury, H., Herson, S., RAFfi, F., \& APROCO STUdy Group (2002). Predictors of long-term increase in CD4(+) cell counts in human immunodeficiency virus-infected patients receiving a protease inhibitor-containing antiretroviral regimen. Journal of Infectious Diseases, 185(4), 471-480.

MacNeil, S. D. \& Fernandez, C. V. (2006). Offering results to research participants. British Medical Journal, 332(7535), 188-189.
McCarty, C. A., Garber, A., Reeser, J. C., \& Fost, N. C. (2011). Study newsletters, community and ethics advisory boards, and focus group discussions provide ongoing feedback for a large biobank. American Journal of Medical Genetics, 155A(4), 737-741.

Miller, F. A., Hayeems, R. Z., Li, L., \& Bytautas, J. P. (2011). What does "respect for persons" require? Attitudes and reported practices of genetics researchers in informing research participants about research. Journal of Medical Ethics. Published Online First on June 16, 2011: http://jme. bmj.com/content/early/2011/06/16/jme.2010.041350.

Moutel, G., Duchange, N., Raffi, F., Sharara, L. I., Théodorou, I., NoËL, V. ET AL. (2005). Communication of pharmacogenetic research results to HIV-infected treated patients: Standpoints of professionals and patients. European Journal of Human Genetics, 13(9), 1055-1062.

Msellati, P., Dupon, M., Morlat, P., Lacoste, D., Pellegrin, J. L., \& Dabis, F. (1990). A cohort study of 89 HIV-1-infected adult patients contaminated by blood products: Bordeaux 1981-1989. Groupe d'Epidémiologie Clinique du SIDA en Aquitaine (GECSA). AIDS, 4(11), 1105-1109.

Murphy, J., Scott, J., Kaufman, D., Geller, G., LeRoy, L., \& Hudson, K. (2008). Public expectations for return of results from large-cohort genetic research. American Journal of Bioethics, 8(11), 36-43.

Shalowitz, D. I. \& Miller, F. G. (2008). Communicating the results of clinical research to participants: Attitudes, practices, and future directions. PLoS Medicine, 5(5), e91.

Smith, W., Grady, C., Krohmal, B., Lazovski, J., \& Wendler, D. For Insight Esprit Group. (2011). Empirical evaluation of the need for "on-going consent" in clinical research. AIDS, 25(1): 107-114.

World Medical Association (WMA). (2008). World Medical Association Declaration of Helsinki: Ethical principles for medical research involving human subjects. 59th WMA General Assembly, Seoul, South Korea. Retrieved from http://www.wma.net/en/30publications/10policies/b3/ index.html. 